\title{
Endogenous EGF maintains Sertoli germ cell anchoring junction integrity and is required for early recovery from acute testicular ischemia/reperfusion injury
}

\author{
Shun Zhang, Yi Zeng ${ }^{1}$, Juan $\mathrm{Qu}^{2}$, Yaning Luo, Xiaohong Wang and Wei $\mathrm{Li}^{3}$ \\ Department of Gynecology and Obstetrics, Reproductive Medicine Center, Tangdu Hospital, Fourth Military Medical \\ University, Xi'an 710038, People's Republic of China, Departments of ${ }^{1}$ Anesthesiology, Xijing Hospital, \\ ${ }^{2}$ Otolaryngology, Xijing Hospital and ${ }^{3}$ Human Anatomy, Histology and Embryology, Fourth Military Medical \\ University, Xi'an 710032, People's Republic of China
}

Correspondence should be addressed to W Li; Email: liweipepeyato@yahoo.com.cn $X$ Wang; Email wangxh-99919@163.com

S Zhang and $\mathrm{Y}$ Zeng contributed equally to this work

\begin{abstract}
Administration of exogenous epidermal growth factor (EGF) improves testicular injury after acute ischemia-reperfusion (IR) stress, but the molecular basis is poorly understood. The role of endogenous EGF in testicular recovery and the underlying intracellular signaling pathways involved were herein investigated. In mice, testicular IR injury significantly enhanced the expression level of endogenous Egf at the very beginning of reperfusion. Expression of EGF receptor (Egfr (ErbB1)) was accordingly upregulated $3 \mathrm{~h}$ after reperfusion. Deprivation of majority of circulated EGF by sialoadenectomy aggravated testicular detriment (especially in pachytene spermatocytes), enhanced germ cell apoptosis, and thereafter resulted in impaired meiotic differentiation after IR insult. Mechanistically, endogenous EGF signaling appeared to be indispensable for the proper maintenance of Sertoli germ cells anchoring junction dynamics during the early testicular recovery. We also provided the in vitro evidences in a well-established rat Sertoli germ cell co-cultures model that the pro-survival effect of endogenous EGF on germ cells in response to testicular IR insult is mediated, at least in part, via the phosphatidylinositol 3-kinase/pAkt pathway. Collectively, our results suggest that the augment of endogenous EGF during the early testicular recovery may act on top of an endocrinous cascade orchestrating the intimate interactions between Sertoli cells and germ cells and may operate as indispensable defensive mechanism in response to testicular IR stress. Future studies in this field would shed light on this complicated pathogenesis.

Reproduction (2013) 145 177-189
\end{abstract}

\section{Introduction}

Testicular torsion and subsequent detorsion of spermatic cord, a common surgical emergency among boys and young men, requires early diagnosis and definitive management to avoid future testicular loss (Kanter 2011). In spite of recent improvements in diagnostic and interventional medical care, altered testicular function and infertility remain significant sequels to this pathology (Taskara et al. 2011). Testicular torsion leads to the recruitment and activation of neutrophils, germ cell-specific apoptosis, and inspiration of reactive oxygen species (ROS), contemporaneously with the retention of functional Leydig cell (LCs) and Sertoli cell (SCs) populations (Turner et al. 2006, Namazi 2008). These findings suggest that testicular torsion has the common features of a classical ischemia-reperfusion (IR) injury. Nevertheless, the molecular mechanism through which these pathological responses are directed and the reason why the function of somatic cells is protected from IR injury remain obscure.

Many growth factors are known to act as general and/or tissue-specific survival factors preventing the onset of apoptosis, among which epidermal growth factor (EGF) is a striking example (Goumenos et al. 2008, Laurina et al. 2009, Qiu et al. 2010, Farkas et al. 2011, Pilmane \& Skagers 2011). This polypeptide of 53 amino acids was first isolated and purified from the submandibular glands of male mice (Carpenter \& Cohen 1990) and is capable of activating EGF receptor (EGFR or ErbB1) tyrosine kinase, which in turn activates intracellular signal transduction, enhances transcription of growth-related genes, and usually promotes cell growth (Narayanan et al. 2012, Tarcic et al. 2012). In testis, EGF immunostaining showed positive results in SCs, pachytene spermatocytes, and round spermatids 
(Radhakrishnan et al. 1992). EGF is able to regulate LC proliferation, steroidogenesis, and SC activity (Bai \& Wilson 2008, Kuijk et al. 2009). Sialoadenectomy (removal of the submandibular glands) reduced the amount of circulating EGF to an undetectable level and thereafter resulted in a dramatic decrease in epididymal sperm storage by as much as 55\% (Liu et al. 1994). On the other hand, overexpression of EGF induces hypospermatogenesis in transgenic mice (Wong et al. 2000). Collectively, these reports suggest that a proper EGF expression is required for the normal completion of spermatogenesis.

Apoptosis, first coined to describe an evolutionarily conserved and highly regulated process of nonfunctional cell death, increases significantly in both ischemic and contralateral intact testes after IR injury (Sukhotnik et al. 2007). More importantly, the extent of apoptosis increases with the duration of the ischemia and subsequently determines the damage to testicular function (Turner et al. 2006). Emerging data point out a direct involvement of EGF pathway in testicular apoptosis. For example, EGF administration to the cryptorchid testis significantly decreases the number of apoptotic germ cells (Kurokawa et al. 2005). The EGF-GF ligands, EGF, transforming growth factor- $\alpha$, and $\beta$-cellulin stimulate DNA synthesis in microdissected stage I segments of rat testis seminiferous tubules in vitro (Wahab-Wahlgren et al. 2003). More recently, it has been shown that supplement of exogenous EGF after testicular torsion improves bilateral testicular injury (Uguralp et al. 2004). Given the anti-apoptotic/ proapoptotic effect of EGF signaling is highly dose dependent (usually low concentrations of EGF promoted proliferation, while high concentrations of EGF induced cell cycle arrest, inhibition of proliferation, and apoptosis) (Zhao et al. 2006), we hypothesize that the endogenous EGF may play an important role during the pathogenesis of testicular IR injury. An experimental study was, therefore, designed to evaluate the effects of deprivation of circulating EGF on testicular IR injury in murine sialoadenectomy model. We also provided in vitro evidences that may be related to the mechanism foundation.

\section{Results}

\section{Testicular IR stress induces endogenous EGF expression in mice}

In the first step, the effect of IR on the expression of endogenous EGF and its receptor was investigated in the murine sialoadenectomy model. During the whole study, the sham-operated mice maintained plasma EGF concentration fairly constant. One week after sialoadenectomy, plasma EGF concentration was beyond the limit of detection $(\sim 0.03 \mathrm{nM})$. Thereafter, plasma EGF concentration continuingly rose up and there were no significant differences between the sialoadenectomized and sham-operated group 4 weeks after surgery (Fig. 1A). Interestingly, we only observed a significant decrease in the intratesticular EGF concentration at the end of 1 week after sialoadenectomy (Fig. 1B). This is as expected because EGF is expressed in many other cells and tissues and, in some of them, EGF expression is upregulated upon sialoadenectomy (Buira et al. 2004). These results collectively prompted us to choose postoperative 1 week as the time-point for the subsequent study. Next, the levels of sex hormones including testosterone, $\mathrm{LH}$, and FSH were assessed given their pivotal roles in the control of spermatogenesis. The levels of both plasma testosterone and intratesticular testosterone were constant during the first 3 weeks after surgery and progressively increased thereafter, with the maximum levels in the postoperative 5-week samples (Fig. 1C and D). By contrast, the level of plasma LH remained significantly low from 4 weeks after surgery afterwards (Fig. 1E). The decrease in $\mathrm{LH}$ in sialoadenectomized mice, 4-6 weeks after IR, is likely to be due to feedback inhibition from the elevated testosterone levels. No significant change was detected in the plasma FSH level (Fig. 1F). Because growth factor pathways have been implicated in various organs in response to IR injury (Casillas-Ramirez et al. 2009, James et al. 2010, Brzozowski et al. 2012), we then evaluated the effect of IR on endogenous EGF and its receptor expression in testis. The plasma EGF remained relatively high along the study period but unexpectedly, no statistical difference was detected (Fig. 1G). Conversely, the concentration of intratesticular EGF began to significantly increase from $1.5 \mathrm{~h}$ after IR stress afterward (Fig. 1H). This stimulatory effect was further confirmed at the transcriptional level. In detail, IR injury significantly enhanced the mRNA expression of endogenous Egf at the very beginning of reperfusion. Expression of Egfr was upregulated $3 \mathrm{~h}$ after reperfusion (Fig. 11). Conversely, this stimulatory effect was totally abolished in the sialoadenectomized testis (Fig. 1J).

\section{Ablation of endogenous EGF enhances the testicular detriment after IR stress}

Testicular atrophy is a common feature of impaired spermatogenesis or infertility (Liberal et al. 2010). In our study, testis/body weight ratio was mildly lowered in sialoadenectomized animals, although there were no significant differences between the sialodenectomized and sham-operated group. However, significant difference in testis/body weight ratio was noted at the $24 \mathrm{~h}$ after IR stress $(3.186 \pm 0.1103$ vs $2.178 \pm 0.2847 \%$; $P<0.05)$, and this difference could be reversed by the supplementary treatment with exogenous EGF (2.031 \pm 0.1486 vs $2.997 \pm 0.1099 \%$; $P<0.05$ ) (Fig. $2 \mathrm{~A}$ ). Morphologically, the sialoadenectomized testis appeared quite normal except that a notable decrease in the mature sperm released into lumen was observed in 

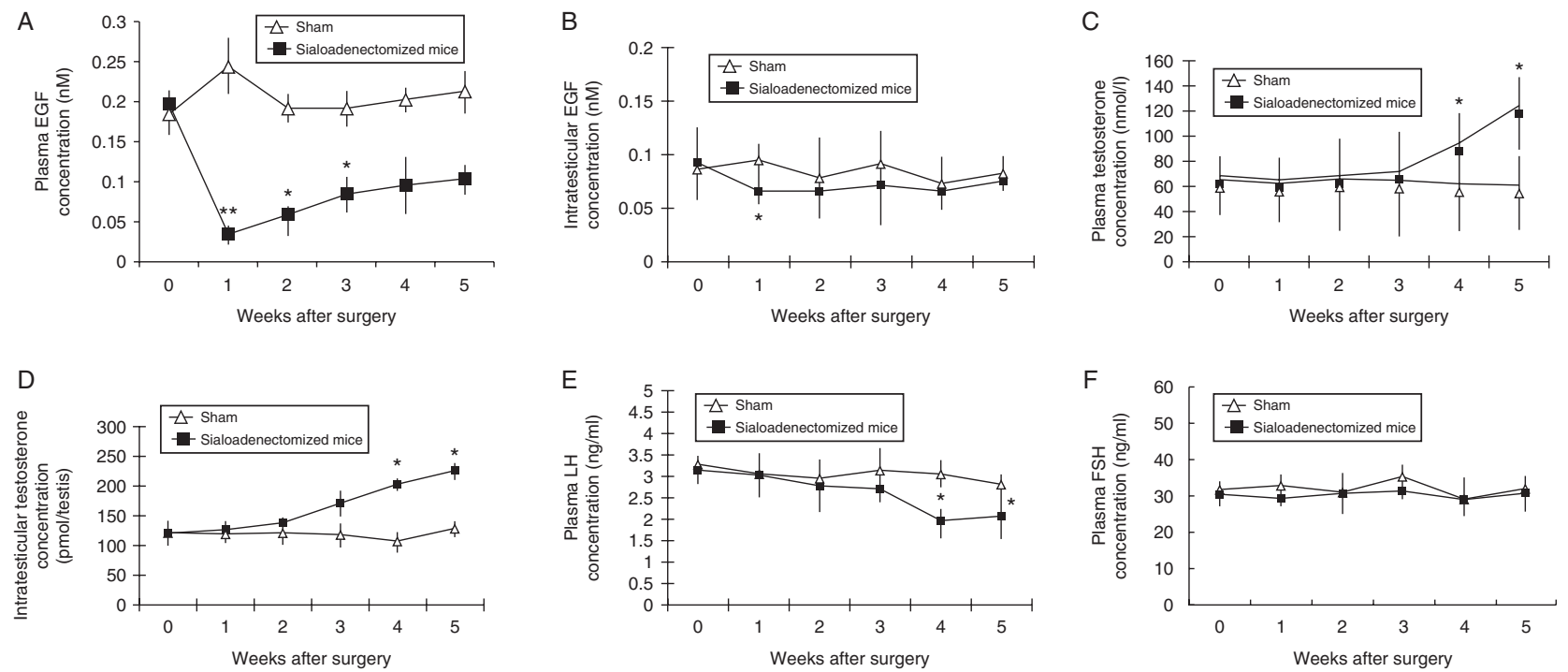

G
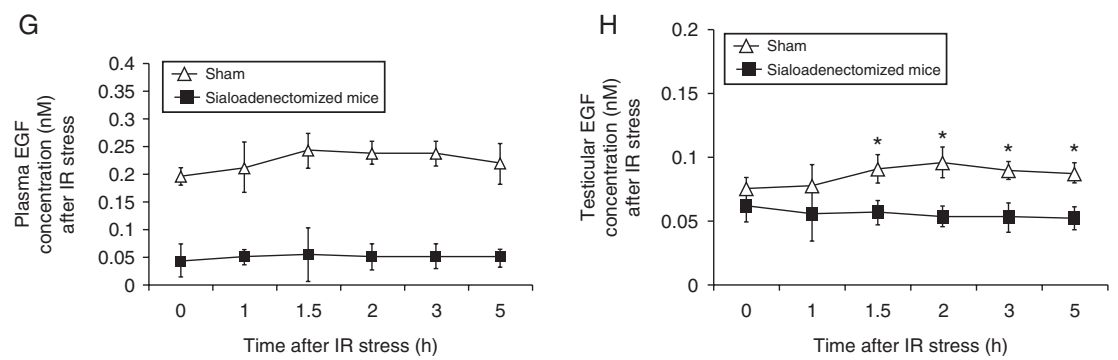

I
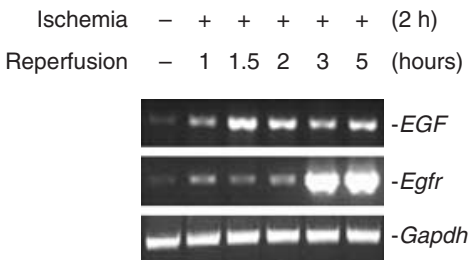

$J$
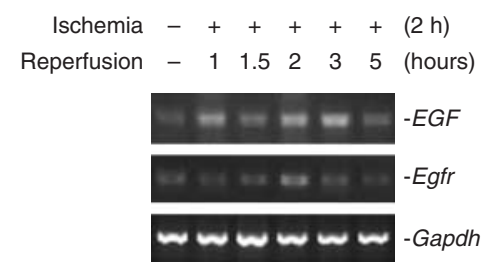

Figure 1 Establishment of murine sialoadenectomy model and its effect on endogenous EGF expression. Adult male mice were either sialoadenectomized (black squares) or sham-operated (white triangles) under sodium pentobarbital anesthesia. At different time-points after surgery, serum and testicular extracts were obtained from both groups and plasma EGF, testosterone, $\mathrm{LH}, \mathrm{FSH}$, and intratesticular EGF and testosterone were assayed as described in the Materials and Methods section (A, B, C, D, E and F). Results are mean \pm S.E.M. of six animals per group. ${ }^{*} P<0.05$ or ${ }^{* *} P<0.01$ between sialoadenectomized and paired-time control value. $(\mathrm{G}$ and $\mathrm{H})$ At different time-points after IR stress, serum and testicular extracts were obtained from sialoadenectomized and sham-operative mice and plasma and intratesticular EGF concentrations were evaluated. Results are mean \pm S.E.M. of six animals per group. ${ }^{*} P<0.05$ between sialoadenectomized and paired-time control value. RT-PCR showed that testicular IR injury induces endogenous Egf expression in sham-operative testis shortly after the beginning of reperfusion. EGF-responsive receptor, Egfr, was also induced at the transcriptional level starting $3 \mathrm{~h}$ after reperfusion (I), whereas sialoadenectomy totally compromised the elevated EGF signaling (J). Amplification of Gapdh mRNAs was served as internal control. Representative results were demonstrated from at least three independent determinations.

hematoxylin and eosin (HE) staining. The seminiferous tubules of sialoadenectomized mice displayed a thinner epithelium, a higher occurrence of germ cell desquamation and epithelial vacuolation and a low intensity of primary spermatocytes (arrows) than the sham-operated tubules $24 \mathrm{~h}$ after IR stress, which could be reversed by application of exogenous EGF (Fig. 2B). The flow cytometric DNA content distribution of various germ cells is well characterized by the presence of three main distinct peaks, representing spermatid (1C, including elongated spermatid and round spermatid), diploid spermatogonia (2C), and primary spermatocyte (4C) populations (Liao et al. 2010). In line with previous report (Tsutsumi et al. 1986), our FACS analysis revealed a significantly increasing percentage of $4 \mathrm{C}$ in sialoadenectomized testis. Interestingly, IR stress completely abolished the accumulation of $4 \mathrm{C}$ spermatocytes and thereafter resulted in a dramatic decrease in primary spermatocytes in sialoadenectomized testis. Replacement with exogenous EGF restored the $4 \mathrm{C}$ percentage to 

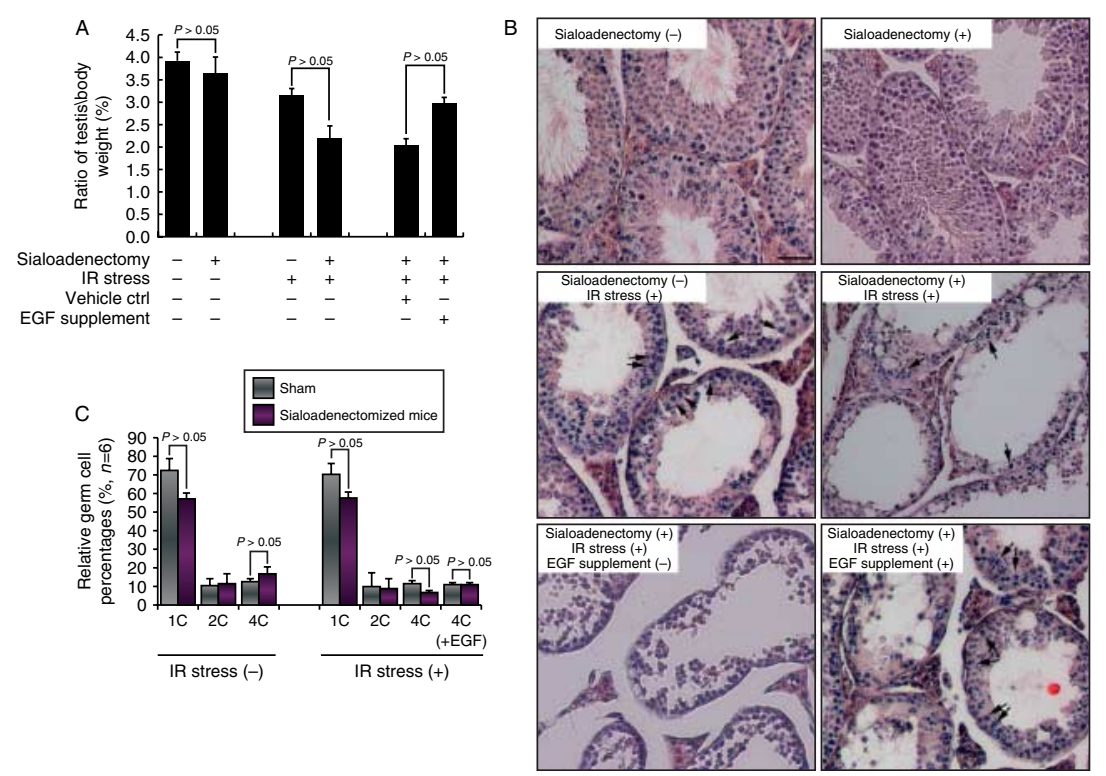

Figure 2 Effect of EGF depletion on testicular damage after IR stress. (A) The sialoadenectomized and sham-operative mice were subjected to testicular IR stress 1 week after sialoadenectomy. Mice were killed at the $24 \mathrm{~h}$ of reperfusion and thereafter testis/body weight ratios were determined. Results are mean \pm s.E.M. of six animals per group. (B) HE staining was carried out to assess the effect of sialoadenectomy on testicular histology at different groups. Arrows indicate pachytene spermatocytes. Bar $=25 \mu \mathrm{m}$. (C) Relative change of germ cell percentage $24 \mathrm{~h}$ after IR was examined by flow cytometry. the normal level, confirming the deleterious effect of IR injury on primary spermatocytes (Fig. 2C). Taken together, these data suggest that the protective effect of endogenous EGF against testicular IR insult mainly occurred during meiosis. The available data made us wonder whether the surviving spermatozoa are capable of inseminating an egg, thereby retaining their reproductive competence. We compared the caudal sperm intensity, sperm motility, and litter size between experimental groups at different time-points after IR stress as described in Table 1. Overall, the fertility potential was reduced in the sialoadenectomized male mice even in the absence of IR stress $\left({ }^{\mathrm{a}} P<0.05\right)$ and the impairment in the fertility induced by IR insult was transient and last $\sim 4$ weeks $\left({ }^{b, c} P<0.05\right)$. By contrast, removal of the majority of endogenous EGF enhanced the testicular detriment after IR stress and resulted in a dramatic decrease in the impregnation rate $\left({ }^{\mathrm{d}} P<0.05\right)$. These results convincingly confirmed that endogenous EGF is an indispensable acute protective mechanism against testicular IR insult.

\section{Ablation of endogenous EGF increases germ cell apoptosis after IR stress and thereafter leads to impaired spermatogenic differentiation}

The death of cells following testicular IR injury is initiated through germ cell-specific apoptotic pathway (Lysiak et al. 2007). We were keen to know whether the above-mentioned observation was due to the upregulation of the apoptotic process induced by testicular IR stress. We quantified the apoptotic rate in different groups using a quantitative ELISA method. As shown in Fig. $3 \mathrm{~A}$, there were dramatic increases of germ cell apoptosis in both sham-operated and sialoadenectomized testes at $24 \mathrm{~h}$ after IR stress, with the higher level in the latter. This elevation of apoptotic wave could be compromised when the animals were supplemented with exogenous EGF. Most of the degenerated germ cells were histologically detected to be primary spermatocytes, whereas few apoptotic spermatids and somatic cells were observed (arrows in Fig. 3B). Because the testicular torsion and subsequent detorsion have been established as a reversible approach for impairment of spermatogenesis, we were then interested to know whether this elevated apoptosis beard any biological effects. We explored the expression levels of genes known to be sequentially tuned in spermatocyte development (Li et al. 2011b). The transcripts from the proacrosin (known to be expressed in mid-pachytene spermatocytes) and cyclin A1 (appearing at the end of prophase of meiosis) were practically decreased in the sialoadenectomized testis when compared with the relatively steady levels in the sham-operated testis at $48 \mathrm{~h}$ after IR stress (Fig. 3C). In addition, we frequently found round spermatids in the caudal epididymis, which was confirmed by the expression of Kdm3a (Jhdm2a) transcripts (blank arrows in Fig. 3D), a specific marker of round spermatids (Okada et al. 2007), in the caudal epididymis at $48 \mathrm{~h}$ after IR stress (Fig. 3D). These data together suggest that the protective effect of endogenous EGF against apoptosis in germ cells is required for both spermatogenic differentiation and cell attachment under the condition of IR stress.

\section{Endogenous EGF contributes to maintain the integrity of testicular anchoring junction after IR stress}

Sialoadenectomized testis exhibits several hallmarks of testicular impairment (elevated epithelium degeneration, increased apoptotic rate inside seminiferous 


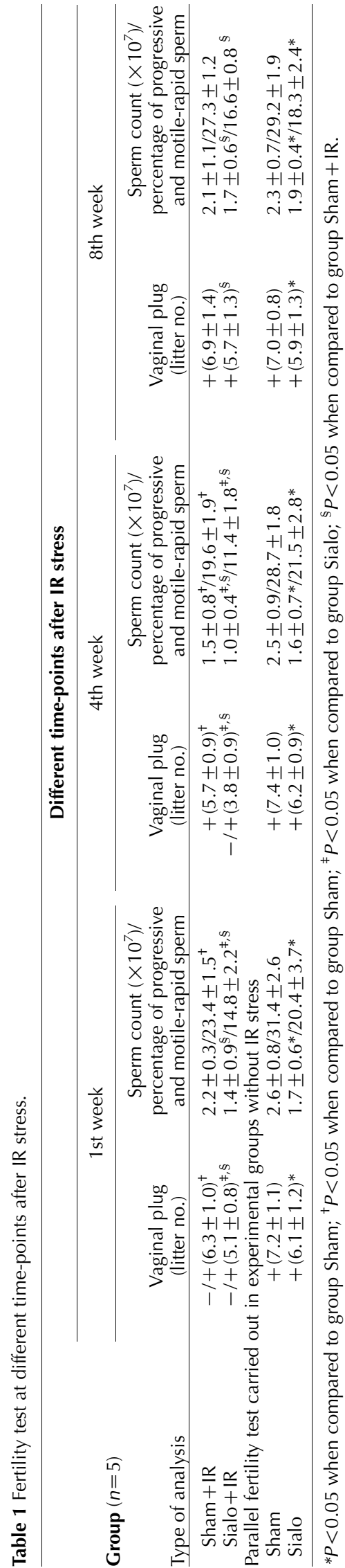

tubules, and germ cell desquamation), suggesting a disruption of SC function. As germ cells exist in an environment created by SCs, paracrine signaling between these intimately associated cells must regulate the process of germ cell death (Boekelheide et al. 2000). These observations promote our belief that the interaction between SCs and germ cells must be disturbed and this disruption may cause the massive germ cell death in our model. We therefore examined various SCs-specific functional genes in the testes of the sialoadenectomized mice using real-time PCR. Interestingly, the expression of most genes was unaffected in the sialoadenectomized group before IR stress (Fig. 4A). However, the expression level in half of the genes observed, among which most of the genes are documented to maintain the functionality of Sertoli germ cell anchoring junction (AJs), was disrupted in the same group after IR stress (Fig. 4B). An attenuated expression pattern of $\mathrm{N}$-cadherin was also confirmed in the testis of sialoadenectomized mice at $4 \mathrm{~h}$ after IR stress by immunohistochemical staining (Fig. 4C). At $4 \mathrm{~h}$ after IR stress, a biologically active FITC-labeled insulin was injected into the interstitium of the testes. The labeled insulin was completely retained in the interstitial space and basal compartment of both sialoadenectomized and sham-operated testes (Fig. 4D). Instead, expression of testin, a specific marker for the disruption of Sertoli germ cell AJs (Grima et al. 1998), was dramatically increased in sialoadenectomized testes $4 \mathrm{~h}$ after IR stress (Fig. 4E and F), suggesting that AJs not TJs were impaired in sialoadenectomized testes after IR stress. It is obvious that endogenous EGF is required for the maintenance of normal dynamics of Sertoli germ cell AJs in response to IR insult.

\section{Pro-survival effect of endogenous EGF in response to testicular IR stress is regulated, at least in part, via the phosphatidylinositol 3-kinase/pAkt pathway}

To further dissect the potential mechanism underlying our observations, we employed a well-characterized SC germ cell co-culture system. When Sertoli and germ cells were co-cultured in vitro in serum-free chemically defined medium, functional AJs were formed within 1-2 days. This event is marked by the upregulated activities of several protein kinases such as phosphatidylinositol 3-kinase (PI3K) and its downstream effector phosphorylated Akt, as well as p21-activated kinase-2 during the early phase of co-culture (Siu et al. 2005). Indeed, induction of the protein levels of pAkt was detected as early as $3 \mathrm{~h}$ after addition of germ cell to the cultured SCs. Protein lysates from 20-day-old SCs cultured for 5 days alone and from freshly isolated germ cells from 90-day-old rats were also applied to immunoboltting analysis to determine the endogenous levels of different target proteins pertinent to AJ formation. Interestingly, a steady induction of pEGFR 


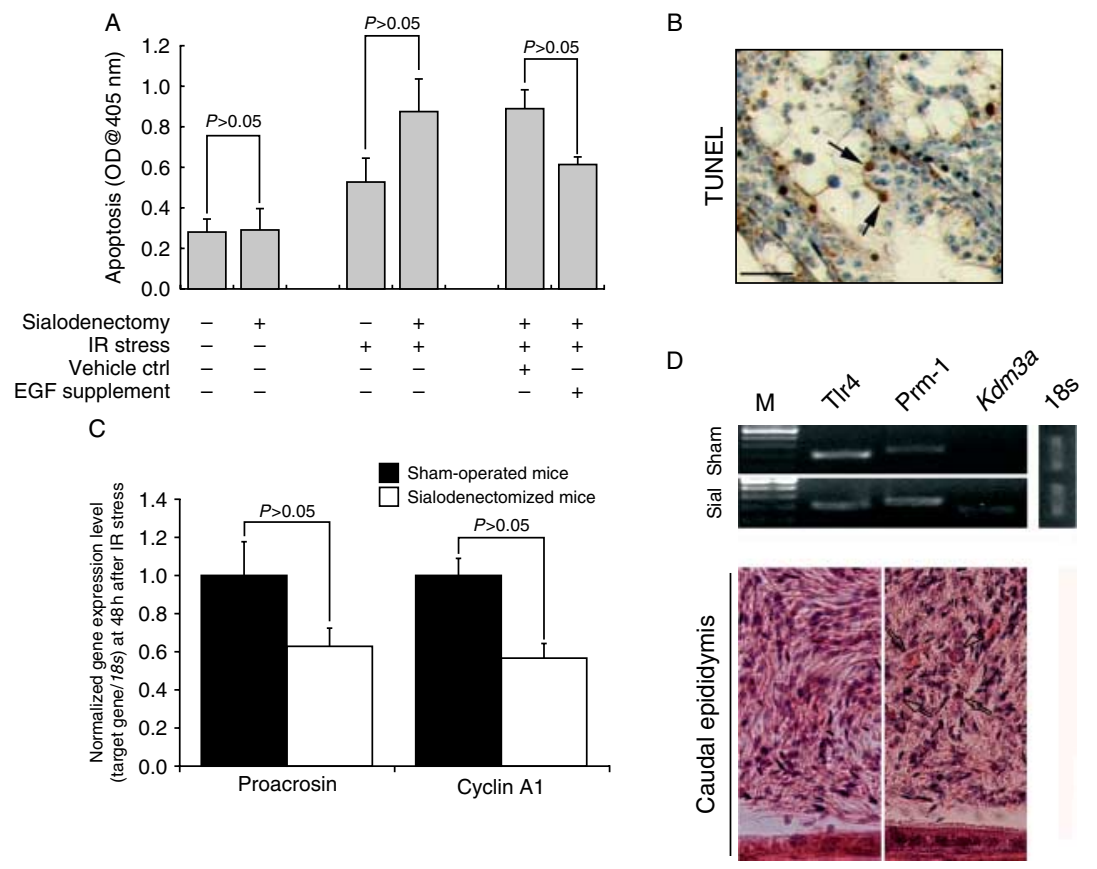

Figure 3 Ablation of endogenous EGF aggravated germ cell apoptosis after IR stress and thereafter led to impaired spermatogenic differentiation. (A) Effect of ablation of endogenous EGF on germ cell apoptosis was evaluated using ELISA methodology at $24 \mathrm{~h}$ of reperfusion. (B) Immunohistochemical demonstration of apoptotic cells (black arrows) in testicular sections from a sialoadenectomized mouse by the TUNEL method. Bar $=25 \mu \mathrm{m}$. (C) The differentiation status of meiotic spermatocytes in different groups was assessed by monitoring the expression level of proacrosin and cyclin A1 at the transcriptional level. Results are mean \pm S.E.M. of six animals per group. $P<0.05$ or $P<0.01$ between sialoadenectomized and paired-time control value. (D) Morphological examination revealed frequent appearance of round spermatids in sialoadenectomized caudal epididymis $24 \mathrm{~h}$ after testicular IR insult, which was confirmed by an unexpected surge of $K d m 3 a$ mRNA expression in caudal epididymis. $18 \mathrm{~s}$ was served as an internal control.

expression was also observed during the early phase of co-culture (Fig. 5A). The EGFRs are known to form homodimers or heterodimers, and signal mainly through MAPK or/and PI3K signaling pathway (Mut et al. 2012). The available data, therefore, implied that EGF may exert its protective effect against testicular IR stress through
PI3K/Akt pathway. To verify this possibility, we subjected the SC germ cell co-cultures into simulated IR stress in the presence or absence of AG1478, a tyrosine kinase inhibitor capable to substantially block EGFR activation (Filosto et al. 2012). Addition of germ cells into cultured SCs resulted in a significant increase in the EGFR

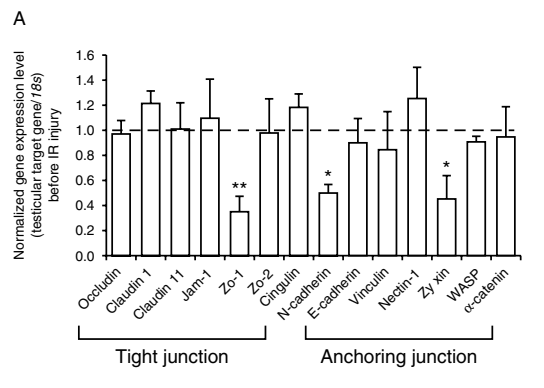

C

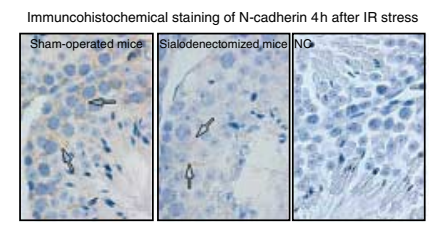

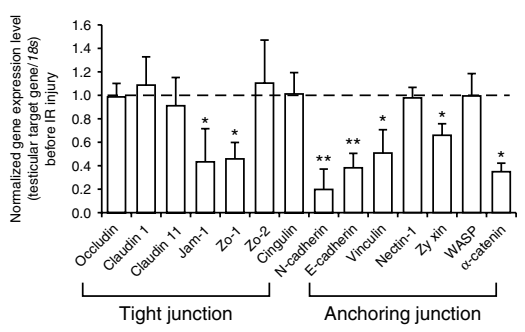

D

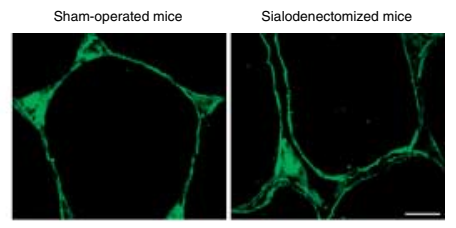

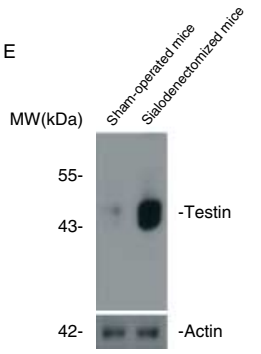

Figure 4 Ablation of endogenous EGF disrupted the anchoring junction (AJ) dynamics during the early recovery after testicular IR stress. (A) Expression profile of AJ components before (A) or after (B) IR stress was evaluated by qRT-PCR analysis at $4 \mathrm{~h}$ after IR. Values are the mean \pm S.E.M. of at least three independent determinations. ${ }^{*} P<0.05$ or ${ }^{* *} P<0.01$ between sialoadenectomized and paired-time control value. (C) An attenuated expression pattern of $\mathrm{N}$-cadherin (empty arrows) was also confirmed by immunohistochemical staining. (D) At $4 \mathrm{~h}$ after IR stress, a biologically active FITC-labeled insulin was injected into the interstitium of the testes. The former was impermeable to the blood-testis-barrier (BTB) in both sialoadenectomized and control testes. (D) By contrast, the expression of testin, a marker of AJ disruption inside seminiferous tubules, was greatly enhanced in sialoadenectomized testis as demonstrated by western blotting analysis (E) and IHC staining (arrow heads in panel F). Bar $=15 \mu \mathrm{m}$. 
A

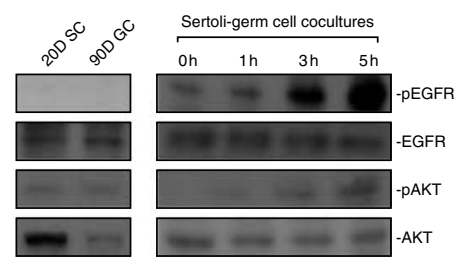

B

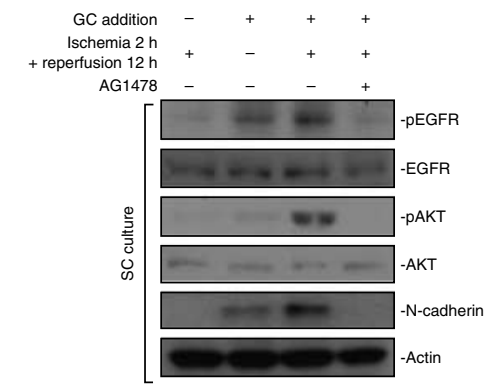

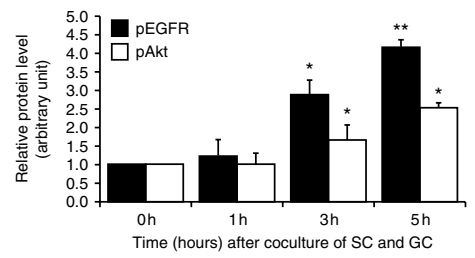

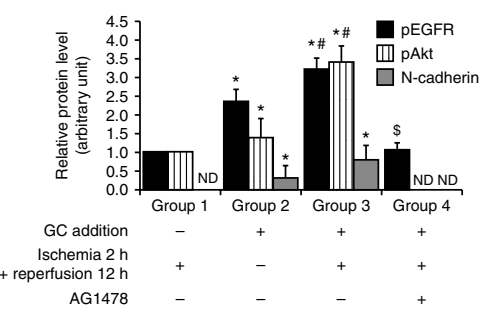

C

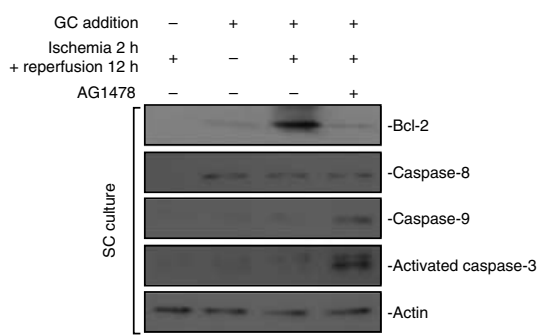

Figure 5 Effect of endogenous EGF in response to testicular IR stress is regulated, at least in part, via the PI3K/p-AKT pathway. (A) Relative protein levels of pEGFR, EGFR, pAKT, and AKT in Sertoli and germ cells and their changes in Sertoli germ cell co-cultures during the assembly of functional AJ vs Sertoli cells cultured alone (control). Densitometric scanning of immunoblots was performed in which the level of a target protein was normalized against the protein level at time 0 , which was arbitrarily set at 1 (A right panels). Each bar represents the mean \pm s.D. of results from three experiments using different batches of cells. Each experiment had replicate cultures. ${ }^{*} P<0.05$, significantly different by analysis of variance; ${ }^{* *} P<0.01$. (B) Relative protein levels of pEGFR, EGFR, pAKT, AKT, and N-cadherin in Sertoli germ cell co-cultures during the simulated IR stress. AG1478 was added into Sertoli germ cell co-cultures to inhibit the activation of endogenous EGF pathway during the reperfusion. Densitometric scanning of immunoblots was performed in which the level of a target protein was normalized against the protein level in Group 1 , which was arbitrarily set at 1 (B right panels). ${ }^{*} P<0.05$ when compared to the level of Group $1 ;{ }^{\#} P<0.05$ when compared to the level of Group $2 ;{ }^{\$} P<0.05$ when compared to the level of Group 3; ND, undetectable. (C) Parallel analysis of apoptotic pathway in the experimental setting as described in panel B was carried out using western blotting. Actin was served as internal control.

activation and of the formation of functional AJs, as evidenced by the upregulated expression levels of pEGFR and $\mathrm{N}$-cadherin respectively. This increasing trend was even more dramatic $12 \mathrm{~h}$ after the co-cultures were subjected to IR stress, well coincident with a remarkable upregulation of pAKT expression. Strikingly, inhibition of EGFR activity via AG1478 treatment abolished the expression of both pAKT and $\mathrm{N}$-cadherin (Fig. 5B). Expression of BCL2 (anti-apoptotic protein) in CO-cultures was significantly upregulated after simulated IR stress, which was totally abrogated by AG1478 treatment. Consistently, the expressions of both caspase-9 and the apoptotic executioner of activated caspase-3 were augmented in IR-stimulated co-cultures in the presence of AG1478. Conversely, expression of caspase-8 remained relatively constant along the study period (Fig. 5C). Thus, endogenous EGF may act on top of an endocrinous cascade orchestrating the intrinsic anti-apoptotic activity of PI3K/Akt signaling in response to testicular IR stress.

\section{Discussion}

The murine sialoadenectomy model has been widely used to investigate the effect of endogenous EGF on the reproductive biology (Dube et al. 2012). In our study, both plasma and intratesticular testosterone levels began to increase at the 4th week after surgery. This is consistent with the previous report that the serum testosterone was significantly reduced in transgenic mice overexpressing hEGF. It remained unlikely that the stimulatory effect of EGF deprivation on testosterone synthesis may stem from evoking of gonadotropic axis at central events as the circulating $\mathrm{LH}$ level was decreased during the late study period. Instead, an autocrine/paracrine feedback of steroidogenesis in response to testicular IR injury is strongly suggested. Furthermore, large volumes of in vitro data have shown the inhibitory effect of EGF on LCs (Manna et al. 2002, Evaul \& Hammes 2008, Shiraishi \& Ascoli 2008). Therefore, it is also possible that 
enhanced testosterone production in sialoadenectomized testis was due to a direct effect of EGF on LC function. Nevertheless, the fact that downregulation of EGF expression was not overlapping with elevated testosterone production in sialoadenectomized testis after IR injury does indicate that EGF action on testicular IR pathogenesis is relatively independent of regulation by sex hormones.

EGF is well known to stimulate cell proliferation and differentiation in a variety of tissues under IR stress. For example, EGF enhances renal tubule cell regeneration and repair and accelerates the recovery of renal function in postischemic acute renal failure. EGF significantly protects against intestinal IR injury. Sustained administration of EGF after testicular torsion improves bilateral testicular injury (Uguralp et al. 2004). Moreover, emerging evidences demonstrated that EGF signaling is able to decrease ROS production, which has been suggested to play an important role during IR pathogenesis, in the intestine, pancreas, and renal tissue (Maeda et al. 2004, Hussein Ael et al. 2011, Zhang et al. 2012). In this context, it was not surprising that testicular IR stress elicited significant increase in EGF activity (Fig. $1 \mathrm{H}, \mathrm{I}$ and $\mathrm{J}$ ), and depletion of endogenous EGF by sialoadenectomy resulted in more dramatic testicular damage after torsion/detorsion. Of note, 8 weeks after $I R$ insult, the impregnation rate of sialoadenectomized mice was much lower than that of sham-operative mice, but one can argue that this is due to the deleterious effect of sialoadenectomy per se because we did not detect significant difference of impregnation rate between Sialo + IR and Sialo groups (Table 1). The relevance of such a phenomenon is presently under investigation, but considering that distribution half-life of EGF in plasma is a few minutes and the elimination half-life is just about an hour (Ellis et al. 2006), it is reasonable to propose that the protective effect of EGF should be transient along testicular IR pathogenesis.

One distinguishing feature in our study is that a significantly increased apoptotic wave involving primary spermatocytes takes place right after IR insult (Figs 2B, C and 3C). Our result is in keeping with Koji et al.'s (2001) work in which testicular torsion/detorsion causes germ cell-specific apoptosis, which is predominantly immunolocalized in the out layer of the rat seminiferous tubules at stages XI-XII, when the meiotic cell division of spermatocytes is underway. This is understandable. The DNA of the spermatocytes in meiosis is most vulnerable to the introduction of a range of errors during the complicated process of spermatogenesis. Cleavage mechanisms (such as apoptosis) are usually initiated to remove those germ cells whose further differentiation has been arrested because of stress condition-induced intrinsic deficiency. However, excessive cell death may result in subsequent impairment of spermatogenic differentiation ( $\mathrm{Li}$ et al. 2011b). Similarly, apoptotic frequency is increased in spermatogenic maturation arrest and hypospermatogenic states of both experimental rodents and human patients (Lin et al. 1997). Therefore, multifactorial mechanisms are warranted in pachytene spermatocytes to ensure the maintenance of proper balance of apoptosis upon stress conditions. This may explain why testicular IR stress significantly enhanced the expression of endogenous Egf from the very beginning of reperfusion in our study as emerging evidences have clearly established EGF as a crucial determinant of cell survival. Together with previous reports that EGF can suppress the apoptosis induced by various stimuli in cultured fetal hepatocytes, mammary epithelial cells, and PC12 cells (El-Assal \& Besner 2005), our data suggest that the anti-apoptotic ability of EGF exists on a broader range and it may serve as negative regulatory mechanism to help to maintain the cellular integrity, especially during meiosis, in response to testicular IR stress.

Testicular AJ is predominantly localized between SCs and germ cells. The main function of AJs is to create a network that maintains tissue integrity and to function in signal transduction events because some of the component proteins of these junctions are signal transducers that relay bidirectional signals to regulate basic cellular processes (Siu et al. 2005). Emerging data have suggested an involvement of AJs in the regulation of germ cell apoptosis. For example, mono-(2-ethylhexyl) phthalate (MEHP) can disrupt vimentin filaments at the site of Sertoli germ cell AJs, which can induce a surge in the expression of testicular Fas receptor and subsequent germ cell apoptosis (Richburg \& Boekelheide 1996). In the present communication, dynamics of Sertoli germ cell AJs was disrupted right after IR insult, evidenced by the attenuated expression profile of AJ-related molecules accompanied by a surge in testin expression. These results also lend support to the above-mentioned notion that functional integrity of AJs is indispensable for early recovery from testicular IR injury. Essentially, the dynamic nature of spermatogenesis requires AJs to act rapidly to extracellular stimuli in order to permit a timely passage of developing germ cells across the seminiferous epithelium from the basal to the adluminal compartment (Yan et al. 2008). Therefore, the half-life of AJs component proteins is usually short and thereby Sertoli germ cell contacts are subject to extensive alteration and remodeling (Cheng et al. 2011). In addition, EGF signaling has been identified as one of the earliest signal transduction events occurring near the cell membrane in response to different stress conditions (Cai et al. 1998, Zhang \& Jope 1999, Murshid et al. 2011). Taken together, our current data open up the possibility that the prominent emergence of endogenous EGF during the early phase of testicular reperfusion may exert its anti-apoptotic effect through modulation of the functionality of AJs.

Despite the well-known pro-survival functions of EGF, the molecular basis of its function on AJ integrity is 
obscure. In the current study, expression levels of both pEGFR and pAkt were significantly induced the time germ cells adhered to SCs in vitro, illustrating the involvement of them in $\mathrm{AJ}$ assembly. The induction of the two kinases could be more dramatic when the co-cultures were subjected to simulated IR stress, contemporaneously with the achievement of AJs formation (evidenced by the expression of $\mathrm{N}$-cadherin). Inhibition of EGFR activity totally abolished the PI3K/Akt pathway and $\mathrm{AJ}$ assembly and then resulted in dramatic increase in intrinsic apoptotic activity. These results clearly demonstrated an indispensable role of EGF/EGFR/PI3K/Akt signaling in the regulation of $\mathrm{AJ}$ dynamics in response to testicular IR injury. Actually, both PI3K and pAKT have been immunolocalized at the site $\mathrm{AJ}$ and apical AJ likely uses these protein kinases as regulatory proteins to modulate Sertoli germ cell junction dynamics (Siu et al. 2005). Furthermore, HB-EGF can enhance the early recovery of intestinal function after intestinal IR stress via PI3K/Akt pathway (El-Assal \& Besner 2005). All together, reinforcement of Sertoli germ cells interaction via EGF/EGFR/PI3K/Akt pathway may represent a potential intrinsic mechanism of early testicular healing after acute ischemic injury in rodents.

On the above-mentioned basis, treatment with exogenous EGF seems to be a simple enforcement of a natural defensive mechanism and to be a possible therapeutic strategy to promote early recovery after testicular IR. Worthy to note, the optimized administration route and administration dosage should be determined in the future study as the effects of EGF on cell proliferation and apoptosis are highly dose dependent. High concentrations of EGF induced both EGFR expression and apoptosis (Zhao et al. 2006). Similarly, transgenic mice overexpressing EGF are characterized by absence or $<10 \%$ of tubules containing cells beyond the pachytene stage and sterile (Wong et al. 2000). Overexpression of EGF can also influence the function of LCs and gonadotropin production (Evaul \& Hammes 2008). Accordingly, the potential side effects of EGF application on testicular biology require for the further investigation.

In summary, endogenous EGF, EGFR, and PI3K/AKT are involved in the intrinsic process of early recovery from testicular IR injury (Fig. 6). Acute IR stress induces a massive germ cell-specific apoptosis, which occurs mainly in the meiotic spermatocytes and may help to remove the defected germ cells after IR insult. However, excessive apoptosis would lead to the disturbance of spermatogenic differentiation and thereafter impair the male fertility. To prevent this deleterious effect, the cross talk between SCs and germ cells is enhanced during the early recovery after testicular IR stress, as the paracrine interactions between these intimately associated cells plays an essential role in the regulation of germ cell apoptosis related to testicular injury. These functions

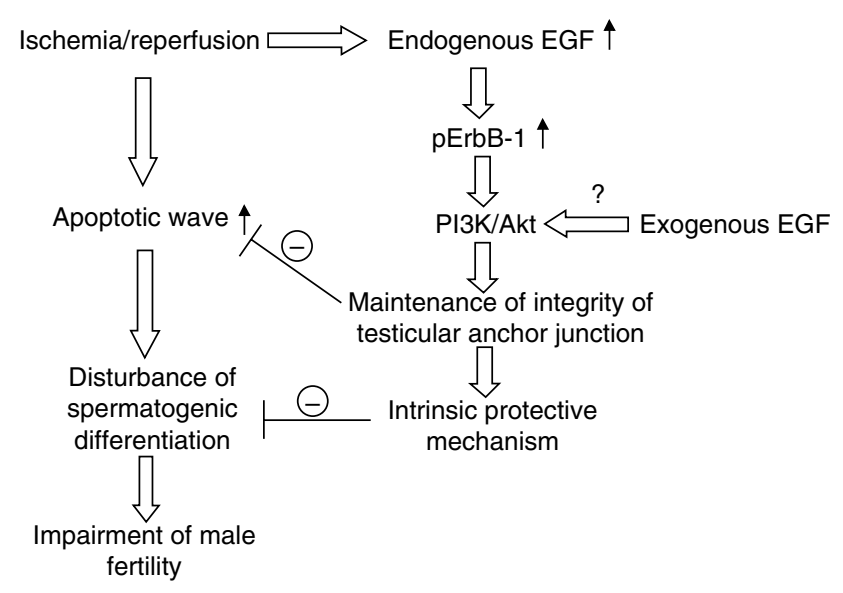

Figure 6 Summary diagram of the possible mechanisms related to endogenous EGF function contributing to maintenance of the integrity of Sertoli germ cell anchoring junction following acute IR stress.

were mediated via activation of ErbB1, with subsequent activation of PI3K/ AKT system, which plays a complementary role in EGF-mediated and intrinsic maintenance of the integrity of functional SC germ cell AJs. Overall, the enhancement of endogenous EGF seems to be a naturally occurring, indispensable defensive mechanism in response to testicular IR stress. Future achievement of in-depth knowledge on this field would certainly herald a synthetic understanding of this very complex pathogenesis.

\section{Materials and Methods}

\section{Ethics statement}

All animal work was approved by the Animal Care and Use Committee of the Fourth Military Medical University and the protocols were strictly conformed to the Guide for the Care and Use of Laboratory Animals published by the National Institutes of Health (NIH publication No. 85-23, revised 1996). All surgery was performed under sodium pentobarbital anesthesia (0.04-0.05 mg/g body weight, i.p.), and all efforts were made to minimize suffering.

\section{Establishment of animal models}

Sexually mature C57/BL6 male mice (10 weeks of age) were obtained from the Animal Research Center of the Fourth Military Medical University, Xi'an (China), they were fed ad libitum, and maintained under a constant $12 \mathrm{~h}$ light: $12 \mathrm{~h}$ darkness cycle (lights on at $0800 \mathrm{~h}$ ) and controlled conditions of humidity (between 70 and $80 \%$ ) and temperature $(22 \pm$ $1{ }^{\circ} \mathrm{C}$ ). They were allowed to acclimatize for at least 1 week before the experiment. Sialoadenectomy was carried out in mice as described previously (Buira et al. 2004). Briefly, a small incision was made to expose the submandibular salivary glands and the tissues were then ligated and excised. The shamoperated mice received the same operation except that the tissues were not ligated and excised. Experimental animals 
were maintained in fasting conditions for the next $24 \mathrm{~h}$. Thereafter, animals had free access to pelleted chow and tap water until they were subjected to testicular IR injury 1 week later. Blood of some sialoadenectomized mice was collected from the inferior vena cava and processed to determine plasma EGF. EGF supplementation began on the first day after sialoadenectomy with the s.c. injection of recombined human EGF (Promega) $(100 \mu \mathrm{g} / \mathrm{kg}$ body weight) consecutively for 7 days. The induction of testicular IR injury was performed in rodent testes according to previous report (Lysiak et al. 2001, Namazi 2008). In brief, the testis was exteriorized through a low midline laparotomy, the gubernaculum was divided, and the testis was separated from the epididymo-testicular membrane. The testis was rotated $720^{\circ}$ for $2 \mathrm{~h}$ (mice), during which time tissues remained in the abdomen with a closed incision. Subsequently, the incision was reopened and the testis was counter-rotated to the normal position. Shamoperated animals were treated identically except that on completion of the torsion maneuver, the testis was immediately counter-rotated. Six males from each group were killed by $\mathrm{CO}_{2}$ asphyxiation at different time-points after surgery as indicated in Figure legends. To evaluate the permeability of testicular tight junctions (TJs) after IR stress, testes were exposed and $50 \mu \mathrm{l}$ FITC-insulin (Invitrogen) was injected under tunica albuginea at $4 \mathrm{~h}$ after IR treatment. Thirty minutes later, testes were harvested, fixed overnight in $4 \%$ paraformaldehyde, and embedded in paraffin. Immunofluorescent signals were finally recovered using Zeiss 510 confocal microscope.

\section{Assessment of male fertility and epididymal parameters}

We investigated the reproductive capacities of experimental mice by mating one male with two females for 2 weeks in multiple trials as indicated in Table 1. Female mice were checked for vaginal plugs each morning and litter sizes were recorded on delivery from three successive matings. The epididymides were removed and minced in $1.5 \mathrm{ml}$ potassium-modified simplex optimized medium and 3\% BSA for $30 \mathrm{~min}$ at $37^{\circ} \mathrm{C}$ to release sperm into the medium. Motility of at least 200 epididymal spermatozoa was assessed by means of light microscopy as described elsewhere (Xu et al. 2007).

\section{Hormone assays}

Levels of testosterone, $\mathrm{LH}$, and FSH were measured by RIA in plasma or in supernatants of total testicular homogenates (Lindzey et al. 1998, Wu et al. 2010). All samples were assayed in duplicate, and each experimental data point consisted of three to six samples. The lower limits of detection for testosterone, $\mathrm{LH}$, and $\mathrm{FSH}$ were $31.58(\mathrm{pg} / \mathrm{ml}), 0.13$, and $1.78(\mathrm{ng} / \mathrm{ml})$ respectively. Intra- and interassay coefficients of variation $(\mathrm{CV})$ were $\sim 8.4$ and $7.2 \%$ respectively for testosterone; 6.6 and $5.1 \%$ for $\mathrm{LH}$ and 4.7 and $2.8 \%$ for FSH. Plasma EGF concentrations were tested by a radioreceptor method, using EGF Radioassay Kits (Biomedical Technologies, Inc., Stoughton, MA, USA) according to manufacturer's instruction. The lower limit of EGF detection was $0.20(\mathrm{ng} / \mathrm{ml})$ and the intraassay CV was about $8.2 \%$.

\section{Preparation and simulated IR stress of rat Sertoli germ cell co-cultures}

SCs were isolated from the testes of 4-month-old rats as described elsewhere (Anway et al. 2003). Cells were plated on 12-well dishes coated with Matrigel (Collaborative Biochemical Products, Bedford, MA, USA) in 1:1 (v/v) nutrient mixture F-12/DMEM and cultured for $48 \mathrm{~h}$ before being subjected to the hypotonic treatment with $20 \mathrm{mM}$ Tris $(\mathrm{pH}$ 7.4) for $2.5 \mathrm{~min}$ to lyse residual germ cells, followed by two successive washes with F-12/DMEM to remove cell debris. The purity of these SC cultures was routinely analyzed by RT-PCR as reported (Siu et al. 2005). Germ cells were isolated from 90-day-old rat and were then added onto the SCs epithelium on day 6 after SCs had been cultured alone for 5 days, forming an intact epithelium. Co-cultures were maintained at a Sertoli/ germ cell ratio of 1:1 to permit ES assembly (Siu et al. 2005). SDS lysis buffer was employed to terminate the co-cultures at the specific time-points as described in Figure legends. To simulate IR, we incubated the co-cultures in ischemic buffer solution (mM: $5.37 \mathrm{KCl}, 0.44 \mathrm{KH}_{2} \mathrm{PO}_{4}, 136.89 \mathrm{NaCl}, 4.166$ $\mathrm{NaHCO}_{3}, 0.338 \mathrm{Na}_{2} \mathrm{HPO}_{4}$, and 5 D-glucose, $\mathrm{pH} 7.3-7.4$ at $37{ }^{\circ} \mathrm{C}$ ) saturated with $95 \% \mathrm{~N}_{2}$ and $5 \% \mathrm{CO}_{2}$. To mimic ischemic conditions, we adjusted the $\mathrm{pH}$ to 6.8 using lactate. The dishes were put into a hypoxic incubator that was equilibrated with $1 \% \mathrm{O}_{2} / 5 \% \mathrm{CO}_{2} / 94 \% \mathrm{~N}_{2}$. After $2 \mathrm{~h}$ of hypoxic treatment, the culture medium was rapidly replaced with fresh F-12/DMEM to initiate reoxygenation ( $\mathrm{Li}$ et al. 2011a). At the $12 \mathrm{~h}$ of reperfusion, co-cultures were harvested and subjected to subsequent immunoblotting analysis.

\section{Flow cytometry}

Germ cells were released from seminiferous tubules in PBS as described elsewhere (Hou et al. 2012). After germ cells were stained with $25 \mathrm{mg} / \mathrm{l}$ ethidium bromide (Sangon Biotech, Shanghai, China), samples were analyzed by flow cytometer with an excitation wavelength of $488 \mathrm{~nm}$.

\section{RNA isolation and qRT-PCR}

Total RNA was extracted from fresh mouse testicular tissue or isolated caudal spermatozoa using Trizol (Invitrogen) and DNA contamination was cleaned using RNeasy MinElute cleanup kit (Qiagen, Inc.) according to the manufacture's instructions. For RT-PCR, first-strand cDNA was synthesized with Superscript III (RNase H-Reverse Transcriptase; Invitrogen) and PCR was set up according to Promega's RT system protocol. The details of primers used in this study were listed in Supplementary Table 1, see section on supplementary data given at the end of this article (Cai et al. 2003, Cooke et al. 2006, Feng et al. 2009, Moik et al. 2011). The amplification of Gapdh or $18 \mathrm{~s}$ mRNAs was served as internal control. PCR products were then quantified by SYBR green intercalation using the MiniOpticon system (Bio-Rad Laboratories, Inc.). Standard curves were constructed for specific targets and $18 \mathrm{~s}$ (internal control) by plotting values of $\mathrm{CT}$ (the cycle at which the fluorescence signal exceeds background) vs log cDNA input (in nanograms). Accordingly, CT values from each experimental sample were 
then used to calculate the amount of specific targets and $18 \mathrm{~s}$ mRNAs relative to the standard. For each sample, results in terms of specific targets expression levels were normalized to those of the internal control $18 \mathrm{~s}$.

\section{Histological examination}

Harvested testes were fixed in Bouin's solution for about $24 \mathrm{~h}$, embedded in paraffin, and were further processed into $5 \mu \mathrm{m}$ thick sections for HE staining.

\section{Immunohistochemistry}

The avidin-biotin-peroxidase (ABC) method was employed in the immunohistochemical assay on serial $5 \mu \mathrm{m}$ sections as described previously (Aydin et al. 2012). Briefly, after endogenous peroxidase activity was blocked with $0.3 \%$ $\mathrm{H}_{2} \mathrm{O}_{2}$ in methanol for 30 min, slides were incubated with the Mouse on Mouse (M.O.M.) blocking solution to eliminate the nonspecific staining (Vector Laboratory, Inc. Burlingame, CA, USA) and then were incubated with the anti-N-CADHERIN mouse antibody (1:100 dilutions; Santa Cruz Biotechnology), diluted in PBS at $4{ }^{\circ} \mathrm{C}$ overnight in a moist box. Biotinylated M.O.M. Anti-mouse Ig (1:600 dilution; Sigma) was incubated for $1 \mathrm{~h}$ at room temperature and detected with streptavidinperoxidase complex. Peroxidases were detected with $0.7 \mathrm{mg} /$ ml 3,3'-diaminobenzidine tetrahydrochloride (Sigma) in $1.6 \mathrm{mg} / \mathrm{ml}$ urea hydrogen peroxide $(60 \mathrm{mmol} / \mathrm{l}$ Tris buffer, $\mathrm{pH}$ 7.6) and the sections were briefly counterstained with hematoxylin. Negative control slides were incubated with pre-absorbing serum.

\section{Western blot}

Protein samples were prepared in ice-cold RIPA buffer (Tris- $\mathrm{HCl} 50 \mathrm{mM}, \mathrm{NaCl} 150 \mathrm{mM}$, Triton X-100 1\% vol/vol, sodium deoxycholate $1 \% \mathrm{wt} / \mathrm{vol}$, and SDS $0.1 \% \mathrm{wt} / \mathrm{vol} \mathrm{pH} 7.5$ ) supplemented with complete proteinase inhibitor cocktail tablets (Roche Diagnostic). Twenty micrograms of protein sample were separated on $8 \%$ SDS/PAGE and transferred to nitrocellulose membrane (Millipore, Bedford, MA, USA). Membranes were then incubated with primary antibodies as indicated in Supplementary Table 2, see section on supplementary data given at the end of this article in blocking solution overnight at $4{ }^{\circ} \mathrm{C}$. Final signals were finally detected using an ECL kit (Amersham Biosciences) according to the manufacturer's instructions.

\section{In situ end-labeling of fragmented DNA}

Apoptotic cells in testicular sections were identified using In Situ Cell Death Detection Kit, POD (Roche Applied Science) following instructions.

\section{Quantification of the apoptotic cells}

An apoptosis ELISA kit (Roche Diagnostics) was used to quantify cytoplasmic histone-associated DNA fragments.

\section{Statistical analysis}

Experiments were repeated at least three times, and one representative from at least three similar results was presented. Comparisons of the difference between groups were performed by ANOVA, with $P<0.05$ being considered as significant. Statistical analyses were performed by using SPSS 13.0 software.

\section{Supplementary data}

This is linked to the online version of the paper at http://dx.doi. org/10.1530/REP-12-0336.

\section{Declaration of interest}

The authors declare that there is no conflict of interest that could be perceived as prejudicing the impartiality of the research reported.

\section{Funding}

This work was supported by the Natural Science Foundation of China (NSFC) (30800395, 31271248) and Science and Technology Research and Development Program of Shaanxi Province (No. 2011K12-01-02).

\section{Acknowledgements}

The authors are indebted to Miss Hui Wang (Department of Foreign Language, the Fourth Military Medical University, Xi'an, People's Republic of China) for her careful assistance during the preparation of the manuscript.

\section{References}

Anway MD, Folmer J, Wright WW \& Zirkin BR 2003 Isolation of Sertoli cells from adult rat testes: an approach to ex vivo studies of Sertoli cell function. Biology of Reproduction 68 996-1002. (doi:10.1095/biolreprod.102.008045)

Aydin S, Sahin I, Ozkan Y, Dag E, Gunay A, Guzel SP, Catak Z \& Ozercan MR 2012 Examination of the tissue ghrelin expression of rats with diet-induced obesity using radioimmunoassay and immunohistochemical methods. Molecular and Cellular Biochemistry 365 165-173. (doi:10.1007/s11010-012-1256-4)

Bai S \& Wilson EM 2008 Epidermal-growth-factor-dependent phosphorylation and ubiquitinylation of MAGE-11 regulates its interaction with the androgen receptor. Molecular and Cellular Biology 28 1947-1963. (doi:10.1128/MCB.01672-07)

Boekelheide K, Fleming SL, Johnson KJ, Patel SR \& Schoenfeld HA 2000 Role of Sertoli cells in injury-associated testicular germ cell apoptosis. Proceedings of the Society for Experimental Biology and Medicine 225 105-115. (doi:10.1046/j.1525-1373.2000.22513.x)

Brzozowski T, Ptak-Belowska A, Kwiecien S, Krzysiek-Maczka G, Strzalka M, Drozdowicz D, Pajdo R, Olszanecki R, Korbut R, Konturek SJ et al. 2012 Novel concept in the mechanism of injury and protection of gastric mucosa: role of renin-angiotensin system and active metabolites of angiotensin. Current Medicinal Chemistry 19 55-62. (doi:10.2174/092986712803413953)

Buira I, Poch E, Sanchez O, Fernandez-Varo G, Grau M, Tebar F, Ramirez I \& Soley M 2004 Sialoadenectomy alters liver cell turn-over and function in mice. Journal of Cellular Physiology 198 12-21. (doi:10.1002/jcp. 10402) 
Cai B, Tomida A, Mikami K, Nagata K \& Tsuruo T 1998 Down-regulation of epidermal growth factor receptor-signaling pathway by binding of GRP78/BiP to the receptor under glucose-starved stress conditions. Journal of Cellular Physiology 177 282-288. (doi:10.1002/(SICl)10974652(199811)177:2 <282::AID-JCP10> 3.0.CO;2-C)

Cai L, Zhang J \& Duan E 2003 Dynamic distribution of epidermal growth factor during mouse embryo peri-implantation. Cytokine 23 170-178. (doi:10.1016/S1043-4666(03)00222-9)

Carpenter G \& Cohen S 1990 Epidermal growth factor. Journal of Biological Chemistry 265 7709-7712.

Casillas-Ramirez A, Zaouali A, Padrissa-Altes S, Ben Mosbah I, Pertosa A, Alfany-Fernandez I, Bintanel-Morcillo M, Xaus C, Rimola A, Rodes J et al. 2009 Insulin-like growth factor and epidermal growth factor treatment: new approaches to protecting steatotic livers against ischemia-reperfusion injury. Endocrinology $\mathbf{1 5 0}$ 3153-3161. (doi:10.1210/en.2008-1458)

Cheng CY, Wong EW, Lie PP, Li MW, Su L, Siu ER, Yan HH, Mannu J, Mathur PP, Bonanomi M et al. 2011 Environmental toxicants and male reproductive function. Spermatogenesis 1 2-13. (doi:10.4161/ spmg.1.1.13971)

Cooke VG, Naik MU \& Naik UP 2006 Fibroblast growth factor-2 failed to induce angiogenesis in junctional adhesion molecule-A-deficient mice. Arteriosclerosis, Thrombosis, and Vascular Biology 26 2005-2011. (doi:10.1161/01.ATV.0000234923.79173.99)

Dube E, Dufresne J, Chan PT \& Cyr DG 2012 Epidermal growth factor regulates connexin 43 in the human epididymis: role of gap junctions in azoospermia. Human Reproduction 27 2285-2296. (doi:10.1093/ humrep/des164)

El-Assal ON \& Besner GE 2005 HB-EGF enhances restitution after intestinal ischemia/reperfusion via PI3K/Akt and MEK/ERK1/2 activation. Gastroenterology 129 609-625. (doi:10.1053/j.gastro.2005.05.054)

Ellis AG, Doherty MM, Walker F, Weinstock J, Nerrie M, Vitali A, Murphy R, Johns TG, Scott AM, Levitzki A et al. 2006 Preclinical analysis of the analinoquinazoline AG1478, a specific small molecule inhibitor of EGF receptor tyrosine kinase. Biochemical Pharmacology $\mathbf{7 1}$ 1422-1434. (doi:10.1016/j.bcp.2006.01.020)

Evaul K \& Hammes SR 2008 Cross-talk between G protein-coupled and epidermal growth factor receptors regulates gonadotropin-mediated steroidogenesis in Leydig cells. Journal of Biological Chemistry 283 27525-27533. (doi:10.1074/jbc.M803867200)

Farkas L, Gauldie J, Voelkel NF \& Kolb M 2011 Pulmonary hypertension and idiopathic pulmonary fibrosis: a tale of angiogenesis, apoptosis, and growth factors. American Journal of Respiratory, Cell and Molecular Biology 45 1-15. (doi:10.1165/rcmb.2010-0365TR)

Feng Y, Sun X, Yang H \& Teitelbaum DH 2009 Dissociation of E-cadherin and beta-catenin in a mouse model of total parenteral nutrition: a mechanism for the loss of epithelial cell proliferation and villus atrophy. Journal of Physiology 587 641-654. (doi:10.1113/jphysiol. 2008.162719)

Filosto S, Becker CR \& Goldkorn T 2012 Cigarette smoke induces aberrant EGF receptor activation that mediates lung cancer development and resistance to tyrosine kinase inhibitors. Molecular Cancer Therapeutics 11 795-804. (doi:10.1158/1535-7163.MCT-11-0698)

Goumenos DS, Kalliakmani P, Tsakas S, Papachristou E \& Vlachojannis JG 2008 Growth factors and apoptosis-related protein expression in human crescentic nephritis. Medical Science Monitor 14 BR243-BR248.

Grima J, Wong CC, Zhu LJ, Zong SD \& Cheng CY 1998 Testin secreted by Sertoli cells is associated with the cell surface, and its expression correlates with the disruption of Sertoli-germ cell junctions but not the inter-Sertoli tight junction. Journal of Biological Chemistry 273 21040-21053. (doi:10.1074/jbc.273.33.21040)

Hou W, Dong Y, Zhang J, Yin Z, Wen H, Xiong L \& Li W 2012 Hypoxiainduced deacetylation is required for tetraploid differentiation in response to testicular ischemia-reperfusion (IR) injury. Journal of Andrology 33 1379-1386. (doi:10.2164/jandrol.112.016584)

Hussein Ael A, Shokeir AA, Sarhan ME, El-Menabawy FR, AbdElmoneim HA, El-Nashar EM \& Barakat NM 2011 Effects of combined erythropoietin and epidermal growth factor on renal ischaemia/reperfusion injury: a randomized experimental controlled study. BJU International 107 323-328. (doi:10.1111/j.1464-410X.2010.09328.x)
James IA, Chen CL, Huang G, Zhang HY, Velten M \& Besner GE 2010 HBEGF protects the lungs after intestinal ischemia/reperfusion injury. Journal of Surgical Research 163 86-95. (doi:10.1016/j.jss.2010.03.062)

Kanter M 2011 Protective effects of Ginkgo biloba (EGb 761) on testicular torsion/detorsion-induced ischemia-reperfusion injury in rats. Experimental and Molecular Pathology 91 708-713. (doi:10.1016/j.yexmp. 2011.09.003)

Koji T, Hishikawa Y, Ando H, Nakanishi Y \& Kobayashi N 2001 Expression of Fas and Fas ligand in normal and ischemia-reperfusion testes: involvement of the Fas system in the induction of germ cell apoptosis in the damaged mouse testis. Biology of Reproduction 64 946-954. (doi:10.1095/biolreprod64.3.946)

Kuijk EW, Colenbrander B \& Roelen BA 2009 The effects of growth factors on in vitro-cultured porcine testicular cells. Reproduction 138 721-731. (doi:10.1530/REP-09-0138)

Kurokawa S, Kojima Y, Mizuno K, Nakane A, Hayashi Y \& Kohri K 2005 Effect of epidermal growth factor on spermatogenesis in the cryptorchid rat. Journal of Urology 174 2415-2419. (doi:10.1097/01.ju.0000180 414.81767.68)

Laurina Z, Pilmane M \& Care R 2009 Growth factors/cytokines/defensins and apoptosis in periodontal pathologies. Stomatologija 11 48-54.

Li HZ, Guo J, Gao J, Han LP, Jiang CM, Li HX, Bai SZ, Zhang WH, Li GW, Wang LN et al. 2011a Role of dopamine D2 receptors in ischemia/ reperfusion induced apoptosis of cultured neonatal rat cardiomyocytes. Journal of Biomedical Science 18 18. (doi:10.1186/1423-0127-18-18)

Li W, Wu ZQ, Zhao J, Guo SJ, Li Z, Feng X, Ma L, Zhang JS, Liu XP \& Zhang YQ 2011 b Transient protection from heat-stress induced apoptotic stimulation by metastasis-associated protein 1 in pachytene spermatocytes. PLoS ONE 6 e26013. (doi:10.1371/journal.pone.0026013)

Liao W, Cai M, Chen J, Huang J, Liu F, Jiang C \& Gao Y 2010 Hypobaric hypoxia causes deleterious effects on spermatogenesis in rats. Reproduction 139 1031-1038. (doi:10.1530/REP-09-0557)

Liberal V, De Miguel MP, Henze M, Nistal M \& Reed SI 2010 Reduced spermatogonial proliferation and decreased fertility in mice overexpressing cyclin E in spermatogonia. Cell Cycle 9 4222-4227. (doi:10.4161/cc.9.20.13544)

Lin WW, Lamb DJ, Wheeler TM, Abrams J, Lipshultz LI \& Kim ED 1997 Apoptotic frequency is increased in spermatogenic maturation arrest and hypospermatogenic states. Journal of Urology 158 1791-1793. (doi:10.1016/S0022-5347(01)64130-2)

Lindzey J, Wetsel WC, Couse JF, Stoker T, Cooper R \& Korach KS 1998 Effects of castration and chronic steroid treatments on hypothalamic gonadotropin-releasing hormone content and pituitary gonadotropins in male wild-type and estrogen receptor-alpha knockout mice. Endocrinology 139 4092-4101. (doi:10.1210/en.139.10.4092)

Liu A, Flores C, Kinkead T, Carboni AA, Menon M \& Seethalakshmi L 1994 Effects of sialoadenectomy and epidermal growth factor on testicular function of sexually mature male mice. Journal of Urology 152 554-561.

Lysiak JJ, Turner SD, Nguyen QA, Singbartl K, Ley K \& Turner TT 2001 Essential role of neutrophils in germ cell-specific apoptosis following ischemia/reperfusion injury of the mouse testis. Biology of Reproduction 65 718-725. (doi:10.1095/biolreprod65.3.718)

Lysiak IJ, Zheng S, Woodson R \& Turner TT 2007 Caspase-9-dependent pathway to murine germ cell apoptosis: mediation by oxidative stress, BAX, and caspase 2. Cell and Tissue Research 328 411-419. (doi:10.1007/s00441-006-0341-y)

Maeda H, Rajesh KG, Suzuki R \& Sasaguri S 2004 Epidermal growth factor and insulin inhibit cell death in pancreatic beta cells by activation of PI3-kinase/AKT signaling pathway under oxidative stress. Transplantation Proceedings 36 1163-1165. (doi:10.1016/j.transproceed.2004.04.018)

Manna PR, Huhtaniemi IT, Wang XJ, Eubank DW \& Stocco DM 2002 Mechanisms of epidermal growth factor signaling: regulation of steroid biosynthesis and the steroidogenic acute regulatory protein in mouse Leydig tumor cells. Biology of Reproduction 67 1393-1404. (doi:10.1095/biolreprod.102.007179)

Moik DV, Janbandhu VC \& Fassler R 2011 Loss of migfilin expression has no overt consequences on murine development and homeostasis. Journal of Cell Science 124 414-421. (doi:10.1242/jcs.075960) 
Murshid A, Theriault J, Gong J \& Calderwood SK 2011 Investigating receptors for extracellular heat shock proteins. Methods in Molecular Biology 787 289-302. (doi:10.1007/978-1-61779-295-3_22)

Mut M, Lule S, Demir O, Kurnaz IA \& Vural I 2012 Both mitogen-activated protein kinase (MAPK)/extracellular-signal-regulated kinases (ERK) $1 / 2$ and phosphatidylinositide-3-OH kinase (PI3K)/Akt pathways regulate activation of E-twenty-six (ETS)-like transcription factor 1 (Elk-1) in U138 glioblastoma cells. International Journal of Biochemistry and Cell Biology 44 302-310. (doi:10.1016/j.biocel.2011.10.025)

Namazi H 2008 Novel molecular mechanism to account for action of taurine against testicular ischemia-reperfusion injury. Urology $\mathbf{7 2}$ 465-466. (doi:10.1016/j.urology.2008.01.068)

Narayanan R, Kim HN, Narayanan NK, Nargi D \& Narayanan B 2012 Epidermal growth factor-stimulated human cervical cancer cell growth is associated with EGFR and cyclin D1 activation, independent of COX-2 expression levels. International Journal of Oncology 40 13-20. (doi:10.3892/ijo.2011.1211)

Okada Y, Scott G, Ray MK, Mishina Y \& Zhang Y 2007 Histone demethylase JHDM2A is critical for Tnp1 and Prm1 transcription and spermatogenesis. Nature 450 119-123. (doi:10.1038/nature06236)

Pilmane M \& Skagers A 2011 Growth factors, genes, bone proteins and apoptosis in the temporomandibular joint (TMJ) of children with ankylosis and during disease recurrence. Stomatologija 13 96-101.

Qiu W, Leibowitz B, Zhang L \& Yu J 2010 Growth factors protect intestinal stem cells from radiation-induced apoptosis by suppressing PUMA through the PI3K/AKT/p53 axis. Oncogene 29 1622-1632. (doi:10.1038/ onc.2009.451)

Radhakrishnan B, Oke BO, Papadopoulos V, DiAugustine RP \& SuarezQuian CA 1992 Characterization of epidermal growth factor in mouse testis. Endocrinology 131 3091-3099. (doi:10.1210/en.131.6.3091)

Richburg JH \& Boekelheide K 1996 Mono-(2-ethylhexyl) phthalate rapidly alters both Sertoli cell vimentin filaments and germ cell apoptosis in young rat testes. Toxicology and Applied Pharmacology 137 42-50. (doi:10.1006/taap.1996.0055)

Shiraishi K \& Ascoli M 2008 A co-culture system reveals the involvement of intercellular pathways as mediators of the lutropin receptor (LHR)stimulated ERK1/2 phosphorylation in Leydig cells. Experimental Cell Research 314 25-37. (doi:10.1016/j.yexcr.2007.06.025)

Siu MK, Wong CH, Lee WM \& Cheng CY 2005 Sertoli-germ cell anchoring junction dynamics in the testis are regulated by an interplay of lipid and protein kinases. Journal of Biological Chemistry $28025029-25047$. (doi:10.1074/jbc.M501049200)

Sukhotnik I, Voskoboinik K, Lurie M, Coran AG, Greenblatt R, Shiloni E, Eldar S \& Mogilner JG 2007 Effect of testicular ischemia-reperfusion on recruitment of neutrophils, E-selectin expression and germ cell apoptosis in the contralateral testis in a rat. Pediatric Surgery International 23 479-485. (doi:10.1007/s00383-006-1854-x)

Tarcic G, Avraham R, Pines G, Amit I, Shay T, Lu Y, Zwang Y, Katz M, Ben-Chetrit N, Jacob-Hirsch J et al. 2012 EGR1 and the ERK-ERF axis drive mammary cell migration in response to EGF. FASEB Journal 26 1582-1592. (doi:10.1096/fj.11-194654)
Taskara E, Gor A, Kutlu O, Karaguzel E, Cobanoglu U, Topbas M \& Senel AC 2011 Does propofol prevent testicular ischemia-reperfusion injury due to torsion in the long term? Pediatric Surgery International 27 1003-1007. (doi:10.1007/s00383-011-2895-3)

Tsutsumi O, Kurachi H \& Oka T 1986 A physiological role of epidermal growth factor in male reproductive function. Science 233 975-977. (doi:10.1126/science.3090686)

Turner TT, Lysiak JJ, Shannon JD, Nguyen QA \& Bazemore-Walker CR 2006 Testicular torsion alters the presence of specific proteins in the mouse testis as well as the phosphorylation status of specific proteins. Journal of Andrology 27 285-293. (doi:10.2164/jandrol.05134)

Uguralp S, Bay Karabulut A, Mizrak B, Kaymaz F, Kiziltay A \& Hasirci N 2004 The effect of sustained and local administration of epidermal growth factor on improving bilateral testicular tissue after torsion. Urological Research 32 323-331. (doi:10.1007/s00240-0040418-6)

Wahab-Wahlgren A, Martinelle N, Holst M, Jahnukainen K, Parvinen M \& Soder O 2003 EGF stimulates rat spermatogonial DNA synthesis in seminiferous tubule segments in vitro. Molecular and Cellular Endocrinology 201 39-46. (doi:10.1016/S0303-7207(03)00002-9)

Wong RW, Kwan RW, Mak PH, Mak KK, Sham MH \& Chan SY 2000 Overexpression of epidermal growth factor induced hypospermatogenesis in transgenic mice. Journal of Biological Chemistry 275 18297-18301. (doi:10.1074/jbc.M001965200)

Wu X, Arumugam R, Zhang N \& Lee MM 2010 Androgen profiles during pubertal Leydig cell development in mice. Reproduction 140 113-121. (doi:10.1530/REP-09-0349)

Xu Q, Lin HY, Yeh SD, Yu IC, Wang RS, Chen YT, Zhang C, Altuwaijri S, Chen LM, Chuang KH et al. 2007 Infertility with defective spermatogenesis and steroidogenesis in male mice lacking androgen receptor in Leydig cells. Endocrine 32 96-106. (doi:10.1007/s12020-007-9015-0)

Yan HH, Mruk DD, Lee WM \& Cheng CY 2008 Cross-talk between tight and anchoring junctions-lesson from the testis. Advances in Experimental Medicine and Biology 636 234-254. (doi:10.1007/978-0-387-09597-4 13)

Zhang L \& Jope RS 1999 Oxidative stress differentially modulates phosphorylation of ERK, p38 and CREB induced by NGF or EGF in PC12 cells. Neurobiology of Aging 20 271-278. (doi:10.1016/S01974580(99)00049-4)

Zhang HY, James I, Chen CL \& Besner GE 2012 Heparin-binding epidermal growth factor-like growth factor (HB-EGF) preserves gut barrier function by blocking neutrophil-endothelial cell adhesion after hemorrhagic shock and resuscitation in mice. Surgery 151 594-605. (doi:10.1016/j. surg.2011.10.001)

Zhao X, Dai W, Zhu H, Zhang Y, Cao L, Ye Q, Lei P \& Shen G 2006 Epidermal growth factor (EGF) induces apoptosis in a transfected cell line expressing EGF receptor on its membrane. Cell Biology International 30 653-658. (doi:10.1016/j.cellbi.2006.04.004)

Received 31 August 2012

First decision 15 October 2012

Accepted 6 December 2012 